\title{
MULHERES, LIDERANÇA POLÍTICA E MEDIA
}

Resenha: Carla Martins. 2015. Lisboa: Alêtheia Editores, 366 pp.

\author{
Maria Helena Santos \\ Instituto Universitário de Lisboa (ISCTE/IUL). Centro de Investigação e de Intervenção Social \\ (CIS/IUL).Email: mhelena.rc.santos@gmail.com
}

\begin{abstract}
Resultado da tese de doutoramento de Carla Martins, realizada na Faculdade de Ciências Sociais e Humanas da Universidade Nova de Lisboa, o livro centra-se em dois contextos marcadamente masculinos - a política e os media - com
\end{abstract} o intuito particular de analisar a liderança política e o jornalismo numa perspetiva de género. Um dos problemas de partida da autora é a invisibilidade das mulheres nos media. Sabendo que no jornalismo a lógica subjacente à notícia é a "notoriedade do agente principal do acontecimento" (p.12), torna-se percetível que, para que as mulheres adquiram visibilidade mediática, não basta que entrem nas instituições políticas, têm de ocupar cargos de maior responsabilidade e poder. Só o desempenho destes cargos deverá assegurar uma presença regular das mulheres nos media. Tal significa, salienta Carla Martins, que as lógicas editoriais contribuem para agravar o efeito do "teto de vidro", já que dão mais voz às pessoas que estão em cargos de topo, onde continuam a chegar poucas mulheres. Com o objetivo de aprofundar os conhecimentos sobre esta problemática, as seguintes questões orientaram a autora: procurar saber se $\mathrm{o}$ sexo dos atores políticos interfere nas práticas discursivas do jornalismo e se a política é genderizada aos olhos das/os jornalistas (p.13).

O laço invisível entre ambos os contextos é mostrado pela autora através de dois estudos de caso: um centrado em Maria de Lourdes Pintasilgo e outro em Manuela Ferreira Leite. Tratam-se de duas figuras com perfis e percursos bastante diferentes, distanciando-se nomeadamente no que diz respeito às "questões das mulheres". Como desenvolverá, o percurso da primeira esteve sempre ligado às lutas pelos direitos das mulheres; no percurso da segunda, tal não se verificou, tendo-se, inclusivamente, manifestado contra as políticas de promoção da igualdade, como é o caso da "Lei das quotas". O facto de estas serem as primeiras mulheres a conseguirem chegar a 
"cargos de responsabilidade na alta política" portuguesa (p.14) levou a que alcançassem uma elevada "notoriedade pública e mediática", que Carla Martins percebeu como sendo o contexto ideal para realizar a sua análise e que, segundo a mesma, lhe permitiria "recensear estilos particulares de liderança construídos e projetados pelos media" (...) e "identificar padrões de cobertura jornalística baseados em assunções de género" (p.15).

O livro está divido em duas grandes partes. A $1^{\mathrm{a}}$ parte, sobre "O género na política e nos media", engloba dois capítulos. No $1^{\circ}$ capítulo, os "Direitos políticos e cidadania feminina" (p.19) são contextualizados historicamente nas sociedades ocidentais e na discussão da pertinência da "categoria de género" para descrever a participação política. Com enorme rigor e clareza, Carla Martins aflora os feminismos para mostrar como a luta das mulheres pela representação política formal foi longa e difícil ao nível internacional, e como não ocorreu ao nível nacional. Se naquele caso a mudança decorreu "de baixo para cima", neste último deu-se "de cima para baixo", o que faz de Portugal um caso especial de análise. Foi o 25 de Abril de 1974 que levou a uma mudança de
Periódico do Núcleo de Estudos e Pesquisas sobre Gênero e Direito

Centro de Ciências Jurídicas - Universidade Federal da Paraíba

V. 6 - Nº 01 - Ano 2017 - Mídia, Gênero \& Direitos Humanos ISSN | 2179-7137 | http://periodicos.ufpb.br/ojs2/index.php/ged/index

paradigma em relação "às bases doutrinárias do ordenamento jurídico, orientada para a igualdade e a garantia das liberdades e direitos fundamentais" (p.48). No entanto, logo se tornou evidente que esta nova ordem jurídicoconstitucional encontraria fortes resistências sustentadas pela ideologia de género vigente, continuando os homens encarregues de "ganhar o pão" e as mulheres remetidas para o lar. Portanto, se as garantias normativas abriram as portas da política às mulheres, estas foram insuficientes para assegurar a igualdade de género nesse contexto, persistindo inúmeras "barreiras invisíveis". As causas destas desigualdades de género são atribuídas a todos os atores envolvidos (homens e mulheres, devido à diferente socialização de género), particularmente ao funcionamento político-partidário.

No $2^{\circ}$ capítulo, é abordado "O poder das representações mediáticas", onde a autora analisa as normas profissionais, os padrões noticiosos de tratamento das mulheres na política e a mobilização de estratégias de comunicação baseadas no sexo. As notícias não são o espelho da realidade, ou como referem Cerqueira, Magalhães, Santos, Cabecinhas, e Nogueira (2014, p.7), os “discursos mediáticos não são 
Periódico do Núcleo de Estudos e Pesquisas sobre Gênero e Direito

Centro de Ciências Jurídicas - Universidade Federal da Paraíba

V. 6 - Nº 01 - Ano 2017 - Mídia, Gênero \& Direitos Humanos ISSN | 2179-7137 | http://periodicos.ufpb.br/ojs2/index.php/ged/index

neutros e abstratos: enquanto práticas que exercem poder (simbólico), são construídos no seio de organizações que estão imbuídas de uma cultura de matriz androcêntrica". Portanto, o discurso jornalístico é genderizado, porque continua a entender o masculino como a "norma" e as mulheres como o "outro". Estas, antes de serem reconhecidas como "políticas", são identificadas como "mulheres", sendo, assim, remetidas para o "lugar delas" (i.e., a esfera privada). As mulheres encontram-se frequentemente num impasse, sendo punidas quer adotem estratégias de comunicação que envolvam comportamentos estereotípicos, quer adotem estratégias que envolvam comportamentos contra-estereotípicos (i.e., há um double bind). Porém, começa agora a verificar-se, aqui e ali, uma cobertura menos estereotipada e mais indistinta de homens e mulheres políticos/as, embora continue a ser dada mais atenção à "mulher" do que à "política".

A $2^{\mathrm{a}}$ parte do livro engloba quatro capítulos. Através da análise de jornais portugueses de informação geral (de periodicidade diária e semanária, de referência e "populares"), a autora trata, então, dois estudos de caso, centrando-se em Maria de Lourdes Pintasilgo e
Manuela Ferreira Leite. No $3^{\circ}$ capítulo, Carla Martins começa por descrever todo o contexto político e jornalístico entre a Revolução de Abril e o final da década de 1970, com o objetivo de perceber as reações à indigitação de Maria de Lourdes Pintasilgo (MLP) como líder do V Governo Constitucional. Este facto não interessou muito as/os jornalistas; houve avanços e recuos na participação das mulheres nos movimentos sociais e na política (partidária). As mulheres foram protagonistas da Revolução de Abril, mas voltaram a ser silenciadas e regressaram à esfera privada. Registouse um retrocesso quer relativamente ao número de mulheres na política, quer à sua visibilidade nos media.

No capítulo seguinte, a autora centra a sua análise em MLP (p.123). Após realizar uma síntese da biografia desta mulher "excecional", analisa os jornais sobre o período do $\mathrm{V}$ Governo para perceber se estes construíram e projetaram algum estilo particular de liderança e padrões de cobertura genderizados no caso de MLP. Em 1979, MLP foi convidada pelo Presidente da República Ramalho Eanes para chefiar o V Governo e aceitou. Analisando cinco jornais - o Diário de Notícias, O Dia, o Diário, o Expresso e O Jornal - eles 
próprios ainda verdadeiros "templos masculinos" -, Martins mostra que o facto de MLP ter sido a primeira mulher (e única, até hoje) a exercer o cargo de primeira-ministra, em Portugal, quebrou a "normalidade" e colocou o género no centro do discurso político e do discurso jornalístico sobre a política. Segundo a autora, esta "novidade histórica" levou à sua mediatização e desencadeou tanto reflexão sobre a participação das mulheres na política, como "estranheza" entre aqueles jornais, nomeadamente de ordem linguística (e.g., no início, era tratada no masculino, como "primeiroministro"). Embora a reflexão ocorrida pudesse ter servido para a consciencialização das desigualdades de género na política, Martins conclui, todavia, que era salientada paralelamente a excecionalidade desta mulher política, cujo perfil contrastava com o padrão da maior parte das mulheres portuguesas da altura (que estavam muito longe de lá chegar). MLP não era apresentada como uma figura claramente masculina, nem representada como feminina. No entanto, as características apontadas estavam mais próximas de um estilo de liderança identificado com o masculino. Perpassa a ideia de que, numa situação de crise, como a que Portugal vivia na altura, uma
Periódico do Núcleo de Estudos e Pesquisas sobre Gênero e Direito

Centro de Ciências Jurídicas - Universidade Federal da Paraíba

V. 6 - Nº 01 - Ano 2017 - Mídia, Gênero \& Direitos Humanos ISSN | 2179-7137 | http://periodicos.ufpb.br/ojs2/index.php/ged/index

214

pessoa com características tão excecionais, juntamente com o facto de ser solteira e com "virtudes católicas", poderia ser capaz de fazer "milagres" pelo país.

No $5^{\circ}$ capítulo, a autora considera o contexto político português entre 1980 e 2009, período de consolidação e "normalização da democracia", revelando "O masculino um pouco menos hegemónico na política" (p.199). Este foi, de facto, um período de altos e baixos, em termos da estabilidade política e das finanças públicas, mas também de grandes mudanças, nomeadamente no que concerne à situação social e política das mulheres, às quais não está alheia a adesão de Portugal à Comunidade Económica Europeia (CEE). Esta adesão marca uma viragem quanto à forma de olhar para a situação das desigualdades entre homens e mulheres na política, que teimavam em persistir, particularmente ao nível dos cargos de poder e de tomada de decisão política. Martins mostra bem como Portugal foi sendo "contagiado" pela valorização da paridade de género e pela perspetiva "gender mainstream", mas somente após o chamado cavaquismo. Neste período, é destacado o caso simbólico do "Parlamento Paritário", realizado por três mulheres de diferentes 
partidos, em 1994, com o objetivo de despertar o interesse dos media para este tema. A perfeita paridade de género experienciada durante dois dias no Parlamento despertou, certamente, o seu interesse. No entanto, como mostra a autora, este só volta a surgir como um tema forte na agenda política no primeiro governo de António Guterres, influenciado pelos ventos de mudança internacionais. $\quad$ A $\quad 4^{\mathrm{a}} \quad$ Revisão Constitucional, em 1997, abriu a porta à introdução de mecanismos de ação positiva na política e, a partir de 1998, são propostas várias leis no sentido de promover a igualdade de género, entre as quais a Lei da Paridade, aprovada em 2006 e implementada em 2009. A autora salienta que tal não ocorreu sem resistências (nomeadamente por parte de Manuela Ferreira Leite), porque, embora houvesse um consenso entre os partidos quanto ao diagnóstico do problema, não havia quanto à solução a adotar para o resolver, como mostram Maria Helena Santos e Lígia Amâncio (2012a, 2012b). Contudo, a própria discussão destas leis conduziu a um crescimento da consciencialização da opinião pública para o tema e serviu para "contagiar" os partidos. Foi, assim, dado outro salto no caminho para a igualdade de género,
Periódico do Núcleo de Estudos e Pesquisas sobre Gênero e Direito

Centro de Ciências Jurídicas - Universidade Federal da Paraíba

V. 6 - Nº 01 - Ano 2017 - Mídia, Gênero \& Direitos Humanos ISSN | 2179-7137 | http://periodicos.ufpb.br/ojs2/index.php/ged/index

entre 1995 e 1999, em todos os domínios onde a lei é aplicada.

Finalmente, Carla Martins centra-se em Manuela Ferreira Leite (MFL), cuja biografia revela uma figura e um percurso diferentes dos de MLP, confirmada pela análise dos jornais Correio da Manhã, Expresso e Público. Entrando para a política por via de Aníbal Cavaco Silva, MFL revela estar na política por dever, devido às “circunstâncias", e não por vocação. Assumiu vários cargos desde 1980, mas Martins centra a sua análise em três deles, considerados "momentos históricos" da política portuguesa, por ser a primeira mulher Ministra das Finanças (em 2002), presidente de um grande partido (eleita líder do PSD em 2008) e candidata às eleições legislativas (em 2009). Segundo a autora, no primeiro momento, um período crítico de desequilíbrio das finanças públicas, MFL é uma figura bastante mediática. Apesar de ser apontada como uma "segunda escolha", a sua nomeação foi, em geral, percebida como positiva entre estes jornais. Havia dúvidas "quanto à sua veia política" (p.255), mas a imprensa reconhecia a sua competência técnica e as qualidades para ocupar o cargo. Nesta altura, é traçado "um perfil predominantemente tecnocrata $\mathrm{e}$ 
masculino de MFL" (p.256). Em 2008, a sua candidatura surge associada a outro momento de crise, desta vez no seio do PSD. Com experiência, MFL assume, mais uma vez, "o encargo de ajudar a resolver a situação" (p.309). Recebendo vários apoios, é agora percebida como "matriarca" de quem é esperado que una e restaure a credibilidade do partido. MFL procura distanciar-se do rótulo de "tecnocrata" e afirma-se como "humanista", incidindo nos temas mais sociais. Porém, recusa as "questões especificamente femininas" (p.269), tendo-se já anteriormente revelado contra as quotas. Em 2009, segundo Martins, ocorre uma mudança: ultrapassados os cenários de crise $\mathrm{e}$ regressada a "normalidade" política, o perfil mediático de MFL a primeiraministra muda, passando já a ser realçada a imagem de "antipolítica". Embora continuasse a ser percebida como uma pessoa digna, perpassa já a ideia de que se trata de uma "mulher" sem "talento" e “jeitinho nenhum” para a política, onde fatores como a "idade" (subjacente à experiência, tão valorizada nos dois momentos de crise) passam a ser apreciados negativamente. Há um double bind claro no caso de MFL, sendo criticada nos jornais quer por exibir comportamentos "masculinos", quer por
Periódico do Núcleo de Estudos e Pesquisas sobre Gênero e Direito

Centro de Ciências Jurídicas - Universidade Federal da Paraíba

V. 6 - Nº 01 - Ano 2017 - Mídia, Gênero \& Direitos Humanos ISSN | 2179-7137 | http://periodicos.ufpb.br/ojs2/index.php/ged/index

exibir comportamentos "femininos" (p.311), percebendo-se que "o referencial de avaliação dos atores políticos continua a ser, objetiva e subjetivamente, masculino" (p.318). Assim, com este livro, a autora mostra que, apesar das mudanças registadas, a política é genderizada, continuando a ser avaliada e representada pelas/os jornalistas como um mundo masculino, o que "influenciou a imagem das duas líderes" (p.320) em análise.

Para concluir, resta-me salientar que - embora estejam ausentes algumas referências centrais para a área do género (e.g., o trabalho de Lígia Amâncio) e do género e media (e.g., o trabalho de Carla Cerqueira) em Portugal, que poderiam ter servido, nomeadamente, para ajudar a clarificar a questão do sexo/género (conceitos, por vezes, usados intermutavelmente) ou para efetuar propostas com vista à promoção de um jornalismo mais inclusivo (Cerqueira et al., 2014) -, considero que este livro é fundamental para quem se interessa pela investigação na área do género, política e media.

\section{Referências bibliográficas}

Cerqueira, Carla; Magalhães, Sara; Santos, Anabela; Cabecinhas, Rosa; 
Nogueira, Conceição (2014), De outro género: propostas para a promoção de um jornalismo mais inclusivo. Braga: CECS/Lasics.

Santos, Maria Helena; Amâncio, Lígia (2012a), "Resistências à igualdade de género na política”, Ex aequo, 25, 45-58.

Santos, Maria Helena; Amâncio, Lígia (2012b), “Género e política: análise sobre as resistências nos discursos e nas práticas sociais face à Lei da Paridade", Sociologia, Problemas e Práticas, 68, 79101. 